\title{
Dynamics of hydrological model parameters: mechanisms, problems, and solution
}

\author{
Tian Lan ${ }^{1}$, Kairong Lin ${ }^{1,2,3}$, Chong-Yu Xu ${ }^{4}$, Xuezhi Tan ${ }^{1,2,3}$, Xiaohong Chen ${ }^{1,2,3}$ \\ ${ }^{1}$ Center for Water Resources and Environment, Sun Yat-sen University, Guangzhou, 510275, China. \\ ${ }^{2}$ Guangdong Engineering Technology Research Center of Water Security Regulation and Control for Southern China, \\ Guangzhou 510275, China. \\ ${ }^{3}$ School of Civil Engineering, Sun Yat-sen University, Guangzhou, 510275, China. \\ ${ }^{4}$ Department of Geosciences, University of Oslo, P.O. Box 1047, Blindern, 0316 Oslo, Norway \\ Correspondence to: Kairong Lin (linkr@mail.sysu.edu.cn)
}

\section{Contents of this file}

1 HYMOD model

2 SCE-UA

3 Violin plot

4 Evaluation results of model performance in Mumahe basin and Xunhe basin

5 Convergence assessment in Mumahe basin and Xunhe basin

References

\section{Introduction}

This supporting information includes five sections that support the analysis. The 1 HYMOD model and 2 SCE-UA algorithm sections are used to support the 3.1 calibration schemes section in the main manuscript. The 3 Violin plot section is used to support the 5.2.1 A tool for convergence evaluation of dynamized parameters section in the main manuscript. The 4 evaluation results of model performance in Mumahe basin and Xunhe basin section is used to account for 4 results section in the main manuscript. The 5 Convergence performance in Mumahe basin and Xunhe basin section is used to supplement 5.2.2 Convergence assessment section in the main manuscript. 


\section{HYMOD model}

The HYMOD model (Moore, 1985; Wagener et al., 2001;Vrugt et al., 2002;Yadav et al., 2007;De Vos et al., 2010;Pathiraja et al., 2018) consists of a simple rainfall excess model based on the probability-distributed moisture store which characterizes the catchment storage as a Pareto distribution of buckets of varying depth as the soil moisture accounting component. It routes

5 through three parallel tanks for quick flow and a tank for slow flow and required five adjustable parameters: $H_{U Z}, B, \alpha, K_{q}$ and $K_{S} . X H_{U Z}$ and $X C_{U Z}$ are state variables characterizing the upper soil moisture content; $A E$ is actual evapotranspiration which is calculated by linear correlations between the soil moisture state and the potential evapotranspiration; effP is effective precipitation; $O V$ is excess precipitation to routing module generated from overflow of soil moisture accounting component; See (Moore, 1985) for a detailed description of the soil moisture accounting model; $X_{q 1}, X_{q 2}, X_{q 3}$ and $X_{s}$ are the state variables

10 of the individual tanks of the routing module; $Q_{q}$ and $Q_{s}$ are the flow values generated from the quick- and slow-flow tanks, respectively.

\section{SCE-UA}

The shuffled complex evolution approach (SCE-UA), as an effective global optimization method, is a commonly used algorithm, because it is open source and was the first algorithm aimed specifically at calibrating hydrological models (Khakbaz

15 and Kazeminezhad, 2012;Eckhardt and Arnold, 2001;Duan et al., 1994;Sorooshian et al., 1993). The technical details about the SCE-UA can be shown in the flowchart (see Figure S1) (Duan et al., 1994). In the SCE-UA, the upper limit of the objective function evaluation is set to 10,000 times. All other settings of the SCE-UA technique are the default.

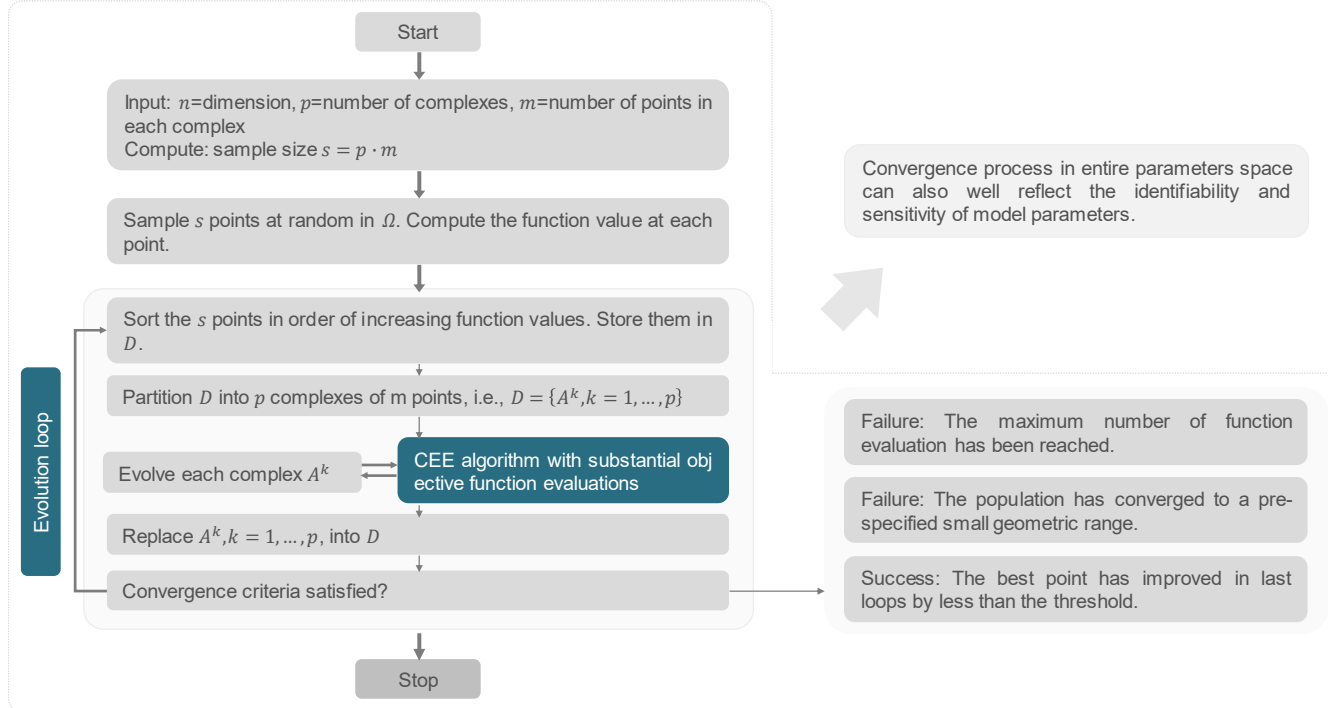

Figure S1. The flowchart of the SCE-UA algorithm (Duan et al., 1994; 1993; 1992). 


\section{Violin plot}

A violin plot is a combination of a Box Plot and a Density Plot showing more details of data distribution. As shown in Figure S2, the thick black bar in the center represents the interquartile range. The white dot represents the median. The thin black line is extended from the thick black bar and represents the $95 \%$ confidence intervals. On each side of the thin black line is a kernel

5 density estimation to show the distribution shape of the data. Wider sections of the violin plot represent a higher probability that members of the population will take on the given value; the skinnier sections represent a lower probability (Hintze and Nelson, 1998). The violin plots can exactly show the kernel density distribution, avoiding the overlapping traditional density plot occur to become difficult to identify. Moreover, unlike bar graphs with means and error bars, violin plots contain all data points, which makes them an excellent tool to visualize samples of small sizes. Violin plots are perfectly appropriate even if

10 your data do not conform to normal distribution. They work well to visualize both quantitative and qualitative data.

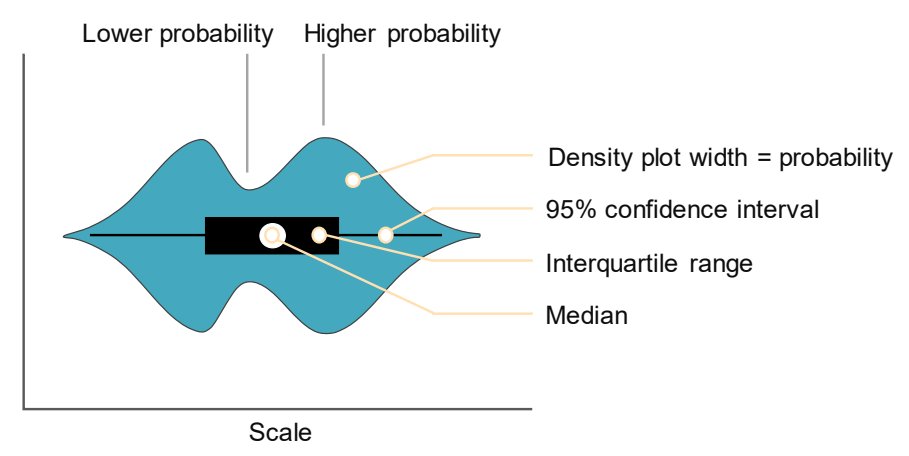

Figure S2. Anatomy of a violin plot

\section{Evaluation results of model performance in Mumahe basin and Xunhe basin}

Table S1. Evaluation results of model performance for scheme 1 and scheme 5 in the Mumahe basin. The best performance is marked 15 red.

\begin{tabular}{|c|c|c|c|c|c|c|c|}
\hline & NSE & LNSE & RMSE_Q5 & RMSE_Q20 & RMSE_mid & RMSE_Q70 & RMSE_Q95 \\
\hline \multicolumn{8}{|c|}{ Calibration } \\
\hline Scheme 1 & 0.691 & 0.445 & 0.953 & 0.357 & 0.118 & 0.554 & 0.909 \\
\hline Scheme 5 & 0.324 & 0.262 & 0.362 & 0.070 & 0.112 & 0.288 & 0.729 \\
\hline \multicolumn{8}{|c|}{ Verification } \\
\hline \multicolumn{8}{|c|}{ Calibration-verification } \\
\hline Scheme 1 & 0.059 & 0.241 & 0.129 & -0.015 & 0.065 & 0.271 & 0.541 \\
\hline Scheme 5 & 0.021 & 0.062 & -0.023 & -0.013 & 0.053 & 0.236 & -0.013 \\
\hline
\end{tabular}

Table S2. The parameter sets of scheme 1 and scheme 5 in the Mumahe basin. 


\begin{tabular}{cccccccc}
\hline & & $H_{\mathrm{uz}}$ & $B$ & alpha & $K_{\mathrm{q}}$ & $K_{\mathrm{s}}$ & \\
\hline \multirow{2}{*}{ Scheme 1 } & & 916.692 & 1.990 & 0.048 & 1.000 & 0.079 \\
\hline \multirow{2}{*}{ Scheme 5 } & Dry period & 999.540 & 1.990 & 0.051 & 0.501 & 0.038 \\
& Rainfall period I & 999.998 & 1.900 & 0.010 & 0.713 & 0.143 \\
& Rainfall period II & 27.799 & 1.990 & 0.010 & 0.801 & 0.237 \\
& Rainfall period III & 644.639 & 1.990 & 0.010 & 0.501 \\
\hline
\end{tabular}

Minimum Maximum

Table S3. Evaluation results of model performance for scheme 1 and scheme 5 in the Xunhe basin. The best performance is marked red.

\begin{tabular}{|c|c|c|c|c|c|c|c|}
\hline & NSE & LNSE & RMSE_Q5 & RMSE_Q20 & RMSE_mid & RMSE_Q70 & RMSE_Q95 \\
\hline Scheme 1 & 0.617 & 0.334 & 0.495 & 0.164 & 0.304 & 0.192 & 0.573 \\
\hline Scheme 5 & 0.252 & 0.183 & 0.165 & 0.153 & 0.157 & 0.166 & 0.724 \\
\hline \multicolumn{8}{|c|}{ Verification } \\
\hline Scheme 5 & 0.253 & 0.258 & 0.186 & 0.071 & 0.076 & 0.092 & 0.292 \\
\hline \multicolumn{8}{|c|}{ Calibration-verification } \\
\hline Scheme 1 & 0.066 & 0.144 & 0.120 & 0.107 & 0.018 & -0.100 & 0.101 \\
\hline Scheme 5 & 0.001 & 0.074 & 0.021 & -0.055 & -0.081 & -0.074 & -0.432 \\
\hline
\end{tabular}

Table S4. The parameter sets of scheme 1 and scheme 5 in the Xunhe basin. The best performance is marked red.

\begin{tabular}{ccccccc}
\hline & & $H_{\mathrm{uz}}$ & $B$ & alpha & $K_{\mathrm{q}}$ & \multicolumn{1}{c}{$K_{\mathrm{s}}$} \\
\hline \multirow{2}{*}{ Scheme 1 } & & 999.991 & 1.259 & 0.342 & 0.894 & 0.024 \\
\hline \multirow{2}{*}{ Scheme 5 } & Dry period & 999.943 & 0.391 & 0.565 & 0.506 \\
& Rainfall period I & 988.154 & 1.602 & 0.031 & 1.000 \\
& Rainfall period II & 353.777 & 0.641 & 0.010 & 0.500 \\
& Rainfall period III & 456.369 & 0.418 & 0.104 & 1.000 & 0.121 \\
\hline
\end{tabular}

5 Minimum Maximum 


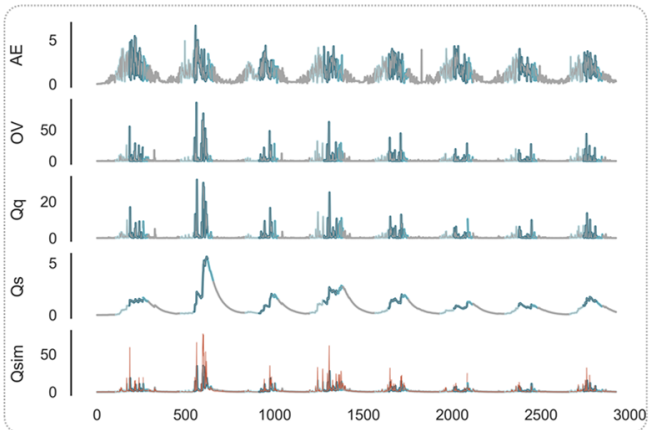

Scheme 2

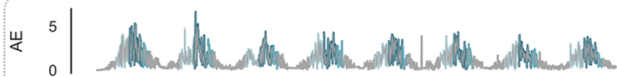

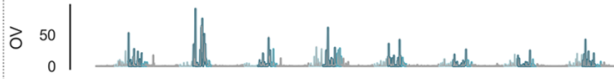

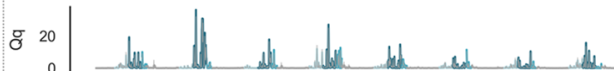
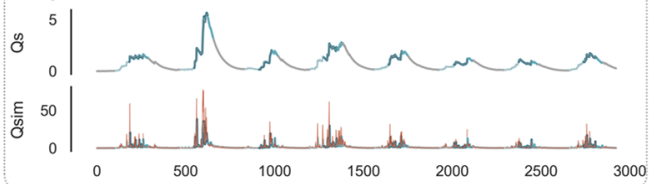

Scheme 3

Scheme 4 or scheme 5

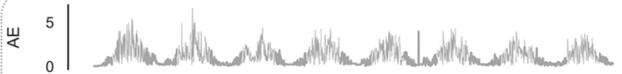

ठ 50

\begin{tabular}{lr|r}
8 & 20 \\
& 0
\end{tabular}

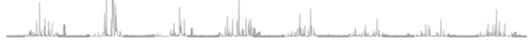

$\begin{array}{ll}8 & 5 \\ 8 & \end{array}$

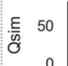
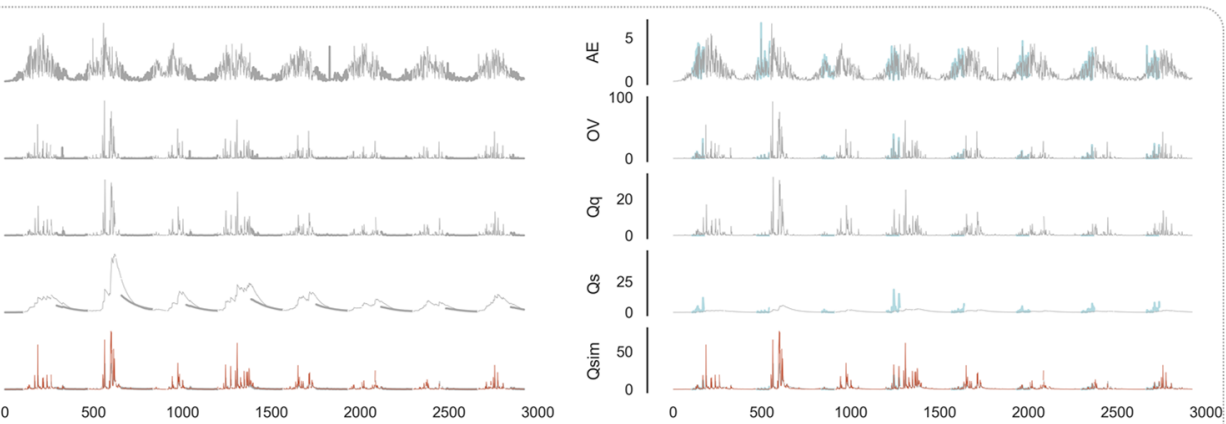

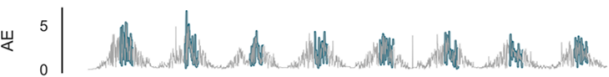

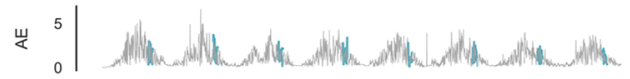

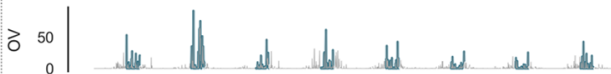

वृ $\begin{array}{rr}20 \\ 0\end{array}$

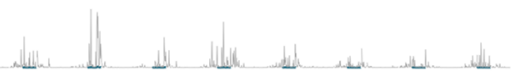

$8_{0}^{50}{ }_{0}^{50}$ an

$\left(\begin{array}{cccc}50 \\ 0\end{array}\right.$
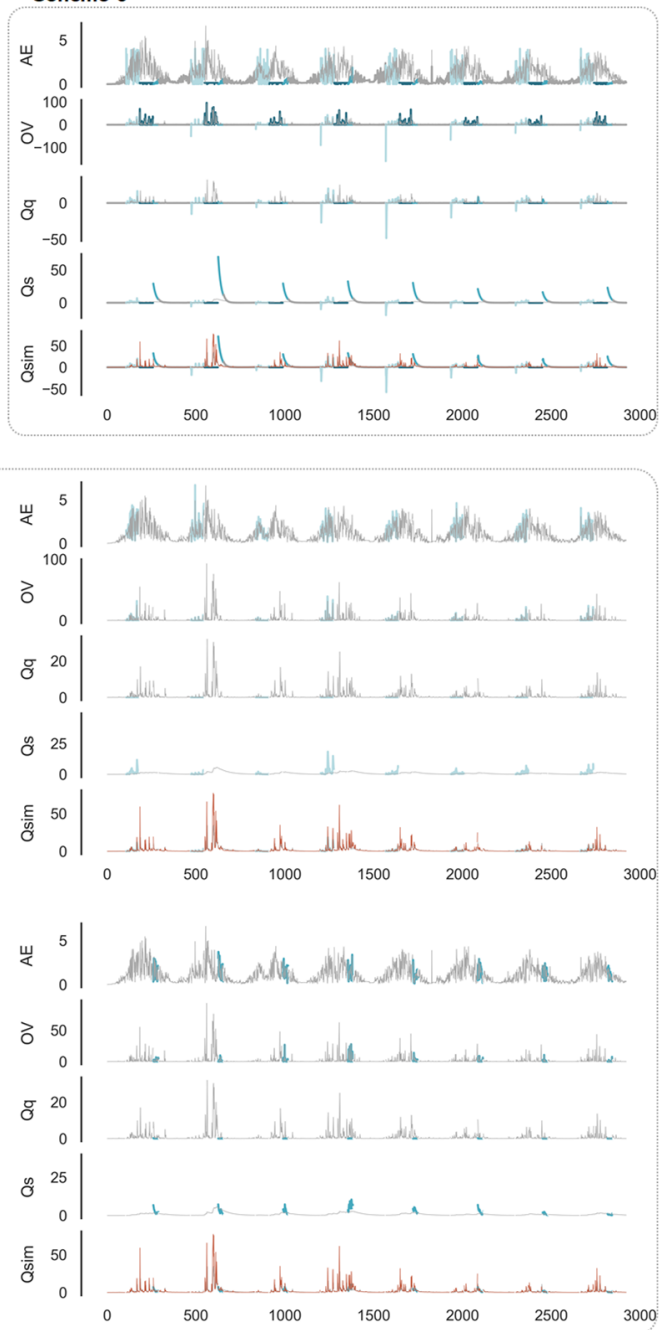

Legend:

- Dry period Rainfall period Rainfall period III

Rainfall period II Scheme 1

Figure S3. Fluxes assessment. All fluxes (including $\boldsymbol{A} \boldsymbol{E}, \boldsymbol{O V}, \boldsymbol{Q}_{\boldsymbol{q}}, \boldsymbol{Q}_{\boldsymbol{s}}$, and $\boldsymbol{Q}_{\boldsymbol{s i m}}$ ) for five schemes in the whole calibration period in Hanzhong basin. 

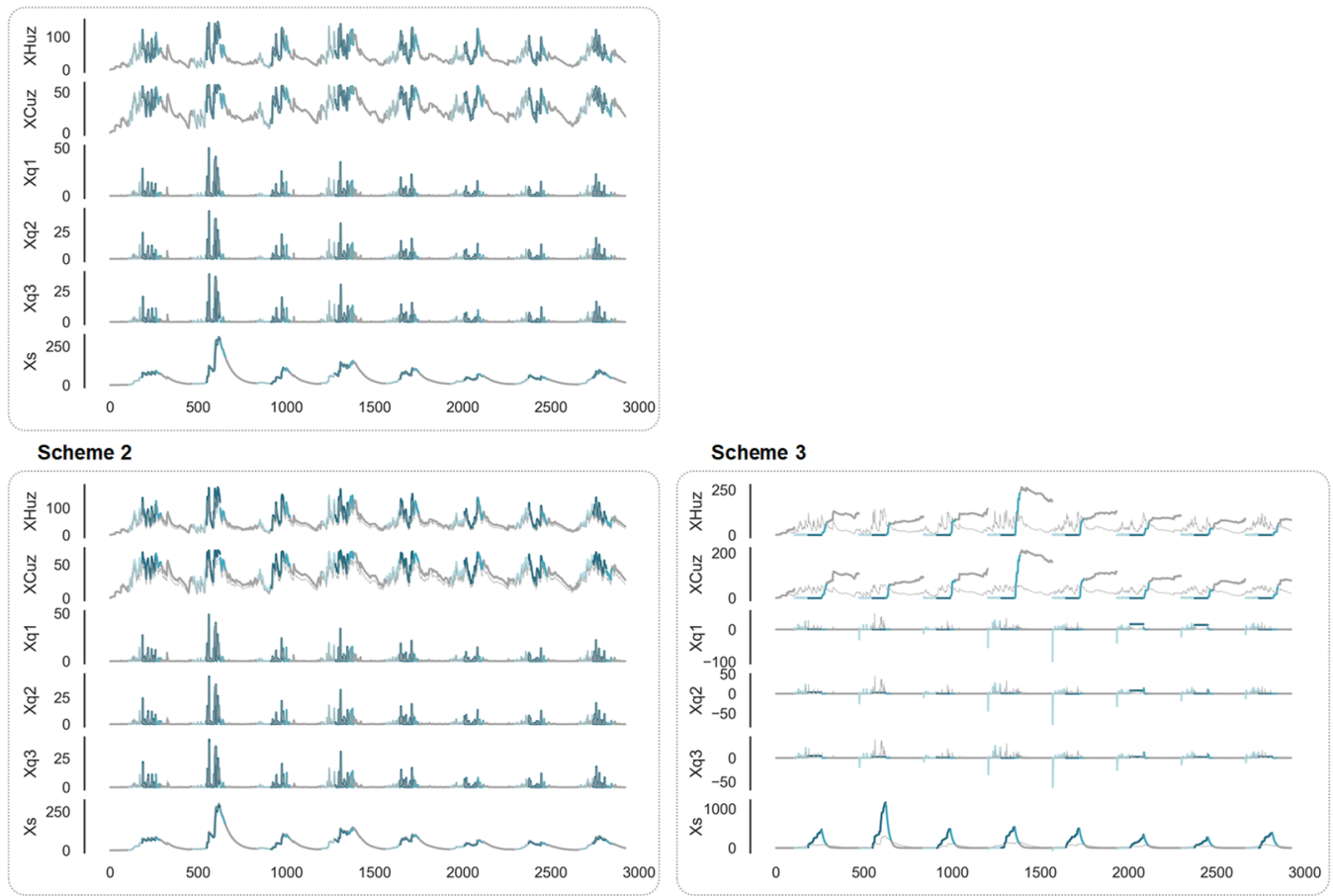

\section{Scheme 4 or Scheme 5}
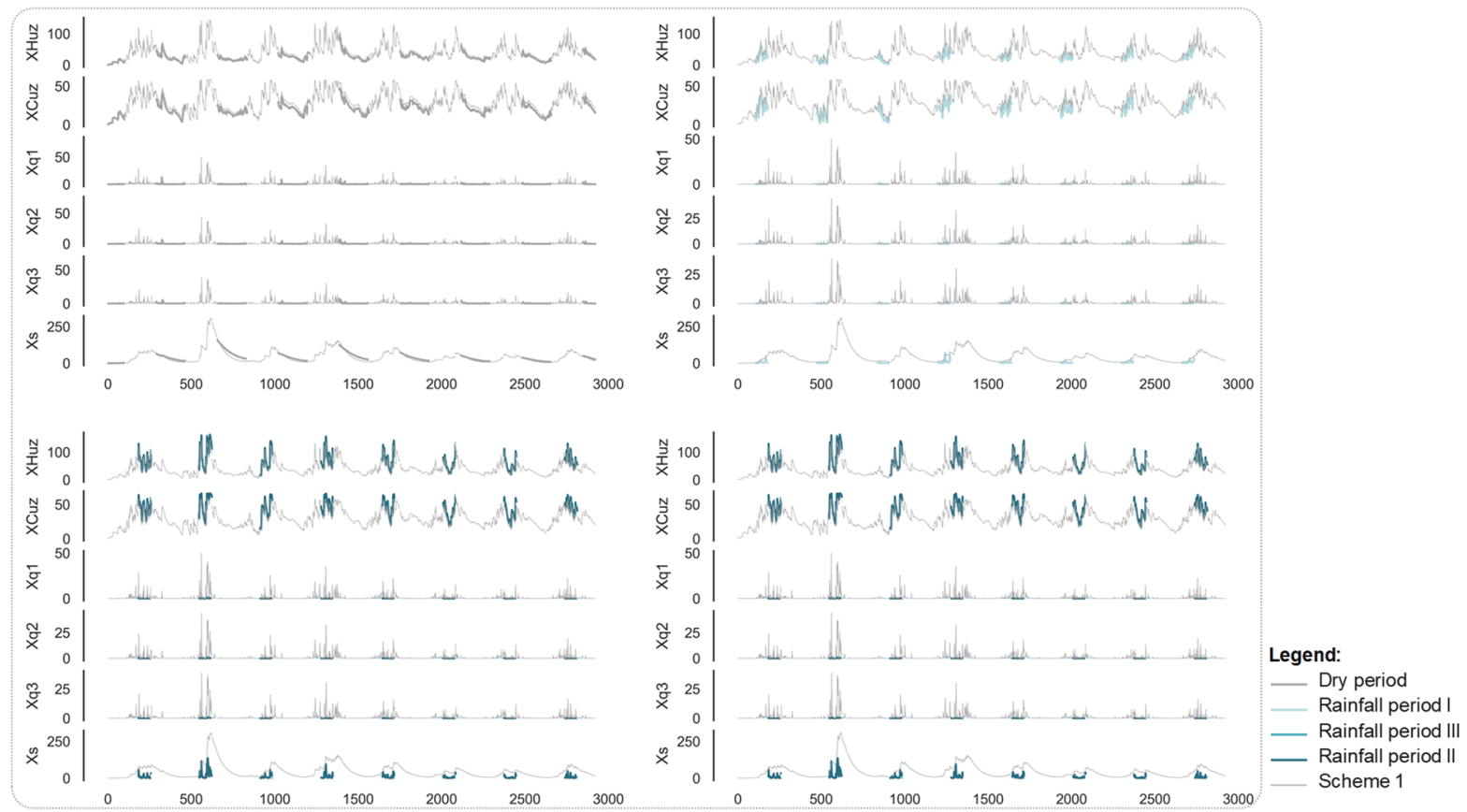

Figure S4. State variables assessment. All state variables (including $\boldsymbol{X H}_{\boldsymbol{U Z}} \boldsymbol{X} \boldsymbol{C}_{\boldsymbol{U Z}} \boldsymbol{X}_{q 1}, \boldsymbol{X}_{q 2}, \boldsymbol{X}_{q 3}$, and $\boldsymbol{X}_{\boldsymbol{s}}$ ) for five schemes in the whole calibration period in Hanzhong basin. 


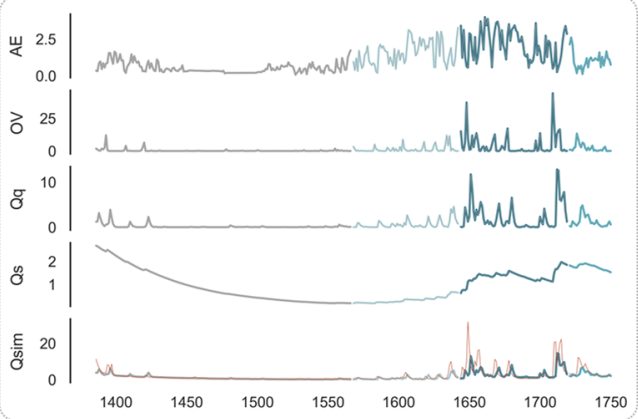

Scheme 2

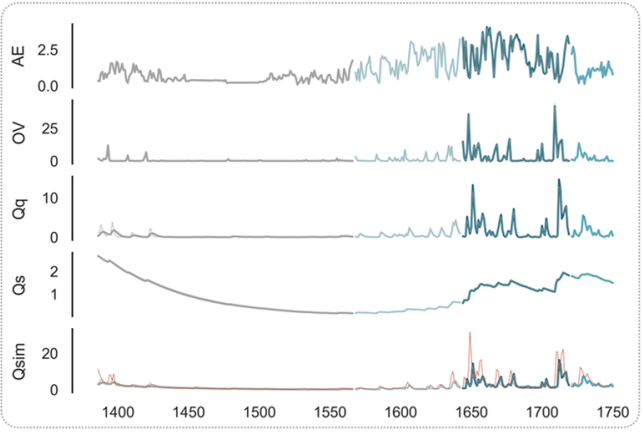

Scheme 3

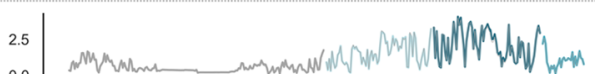
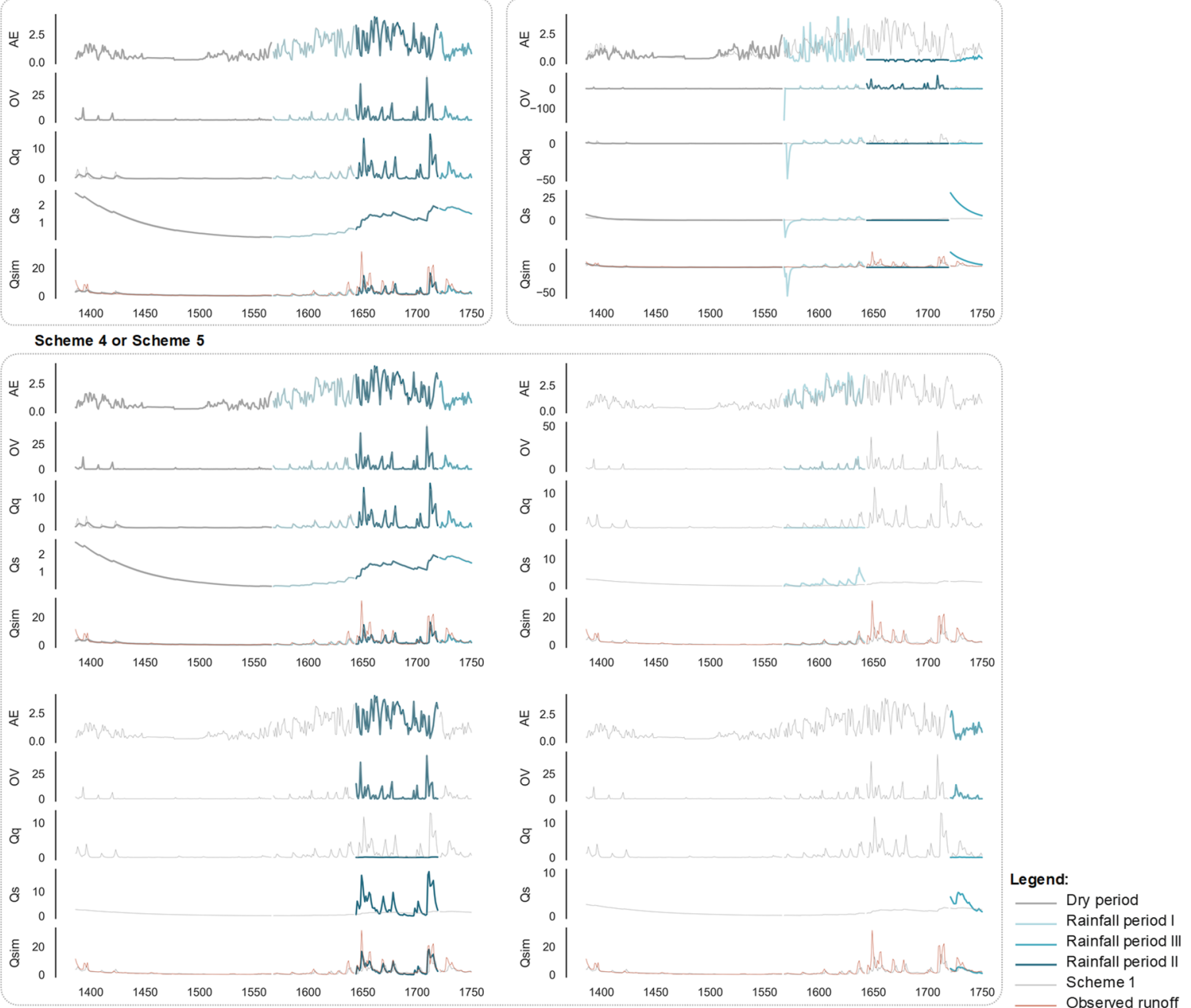

Figure S5. Fluxes assessment. All fluxes (including $\boldsymbol{A E}, \boldsymbol{O V}, \boldsymbol{Q}_{\boldsymbol{q}}, \boldsymbol{Q}_{\boldsymbol{s}}$, and $\boldsymbol{Q}_{\boldsymbol{s i m}}$ ) for five schemes in the calibration period in Hanzhong basin. 

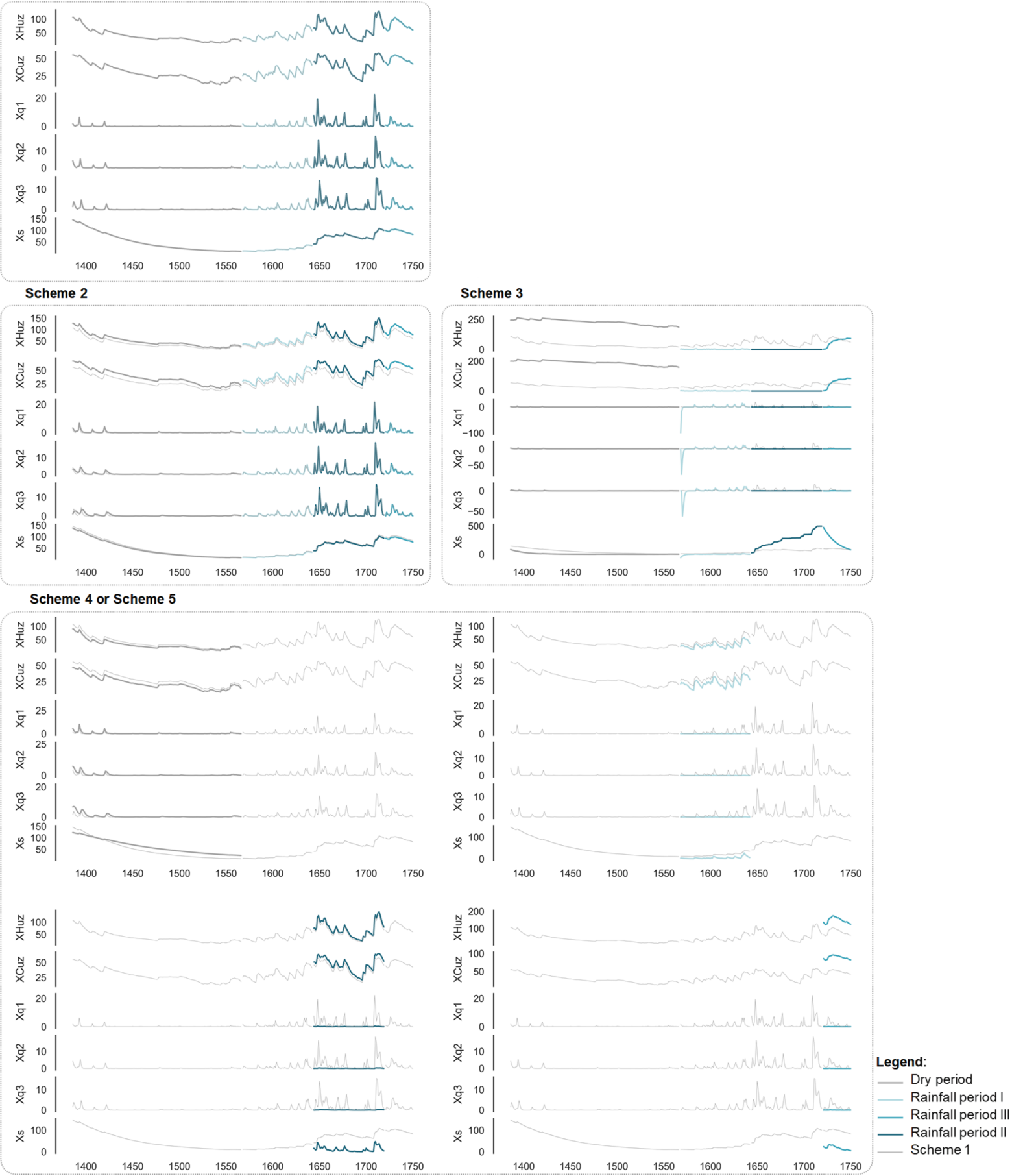

Figure S6. State variables assessment. All state variables (including $\boldsymbol{X H}_{\boldsymbol{U Z}} \boldsymbol{X} \boldsymbol{C}_{\boldsymbol{U Z}} \boldsymbol{X}_{q 1}, \boldsymbol{X}_{q 2}, \boldsymbol{X}_{q 3}$, and $\boldsymbol{X}_{\boldsymbol{s}}$ ) for five schemes in the calibration period in Hanzhong basin. 


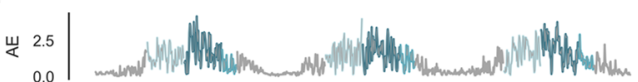
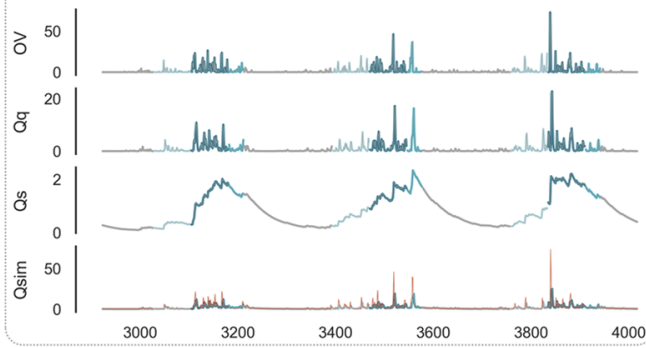

Scheme 3

崖2.5

ठ \begin{tabular}{r|}
50 \\
0
\end{tabular}

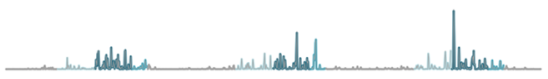

$8^{20}$
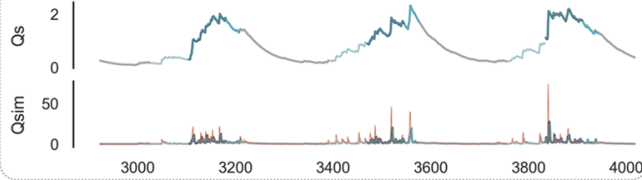

Scheme 4
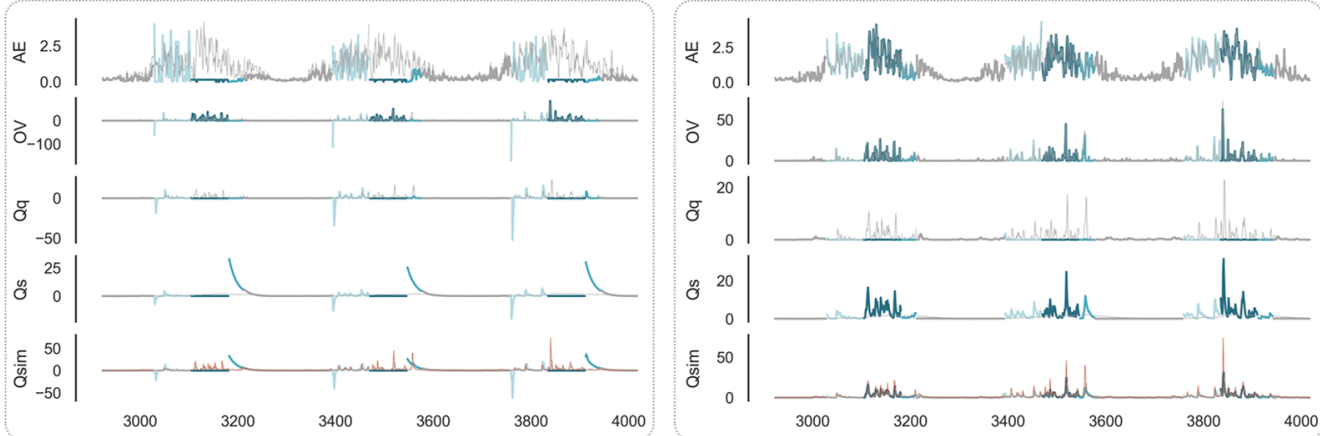

\section{Scheme 5}
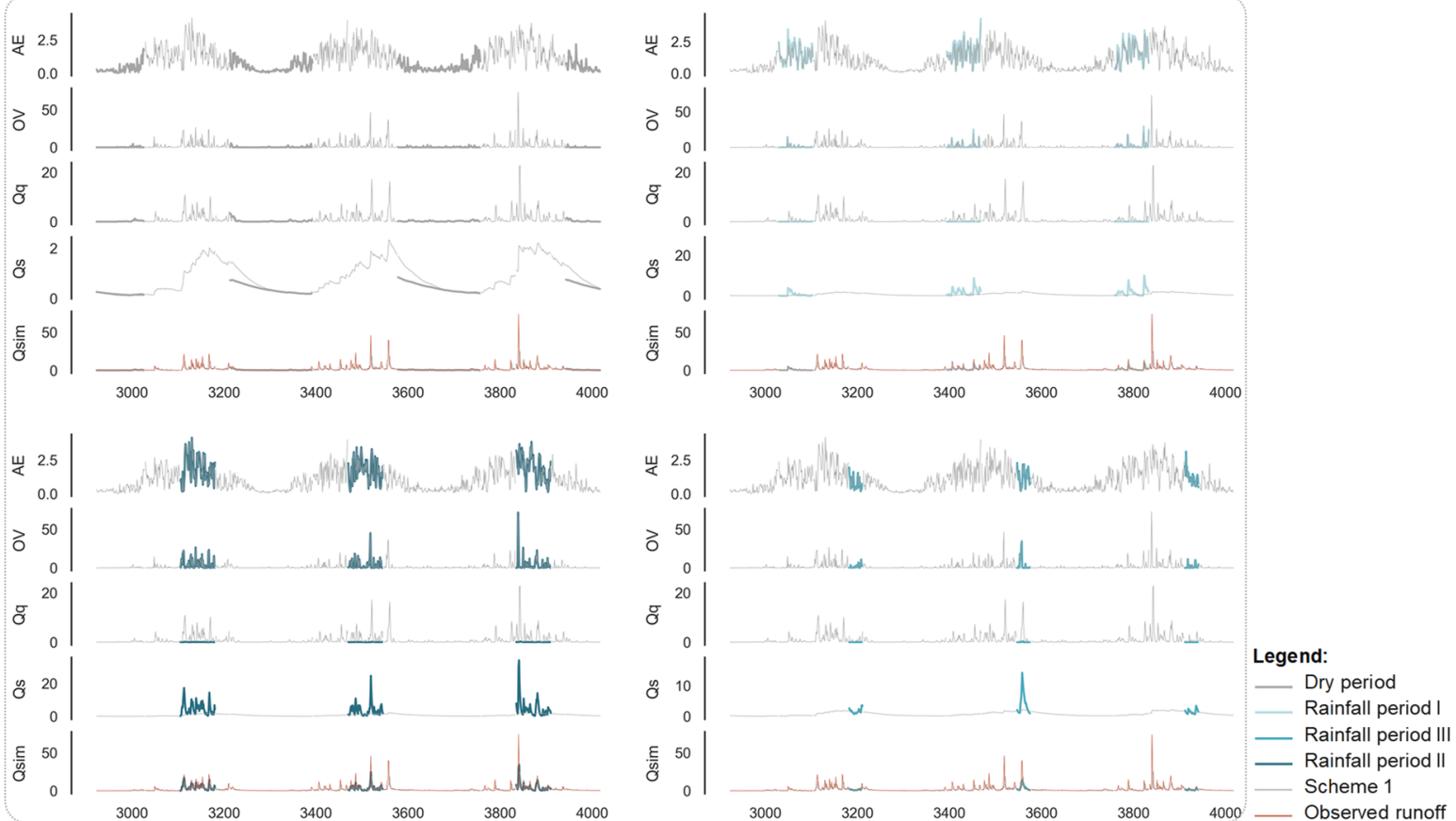

Figure S7. Fluxes assessment. All fluxes (including $\boldsymbol{A} \boldsymbol{E}, \boldsymbol{O} \boldsymbol{V}, \boldsymbol{Q}_{\boldsymbol{q}}, \boldsymbol{Q}_{\boldsymbol{s}}$, and $\boldsymbol{Q}_{\boldsymbol{s i m}}$ ) for five schemes in the whole verification period in Hanzhong basin. 
Scheme 1

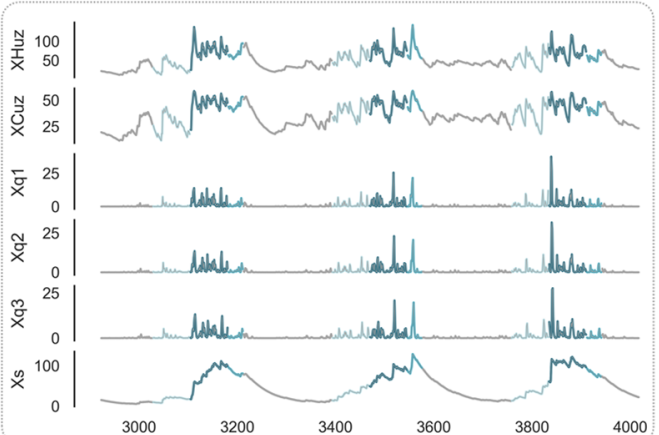

\section{Scheme 3}

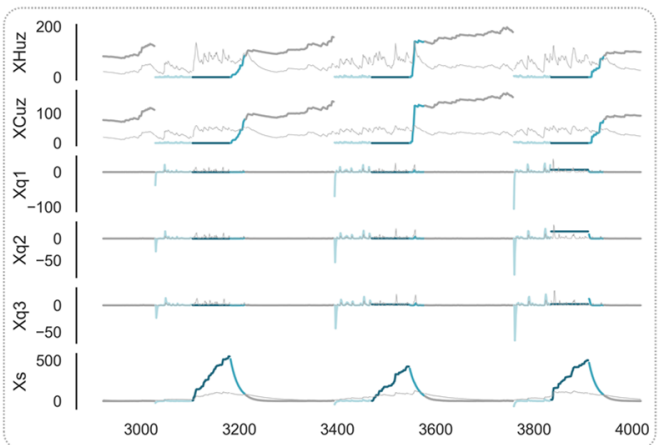

Scheme 5
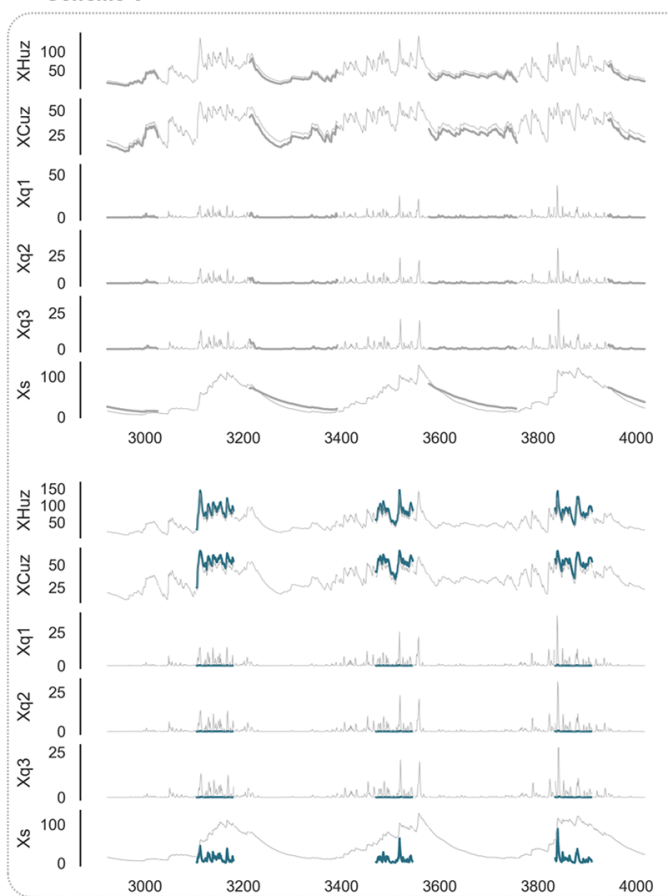

Scheme 2

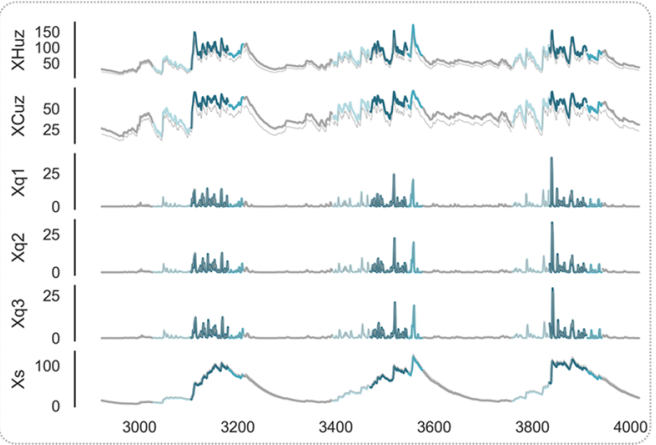

Scheme 4

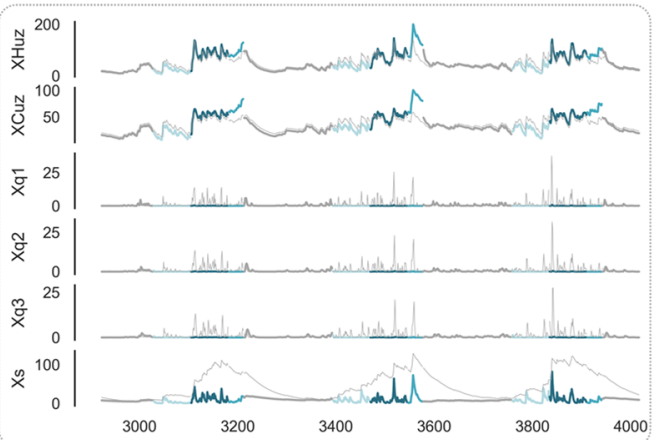

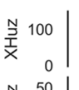

$$
\begin{aligned}
& \begin{array}{ll}
\text { 공 } & 50 \\
\times & 25
\end{array} \\
& \begin{array}{l}
\bar{x} \\
25 \\
0
\end{array} \\
& \text { ₹ै }{ }_{0}^{25} \\
& \stackrel{\mathrm{m}}{x}^{25} \\
& x^{100}
\end{aligned}
$$
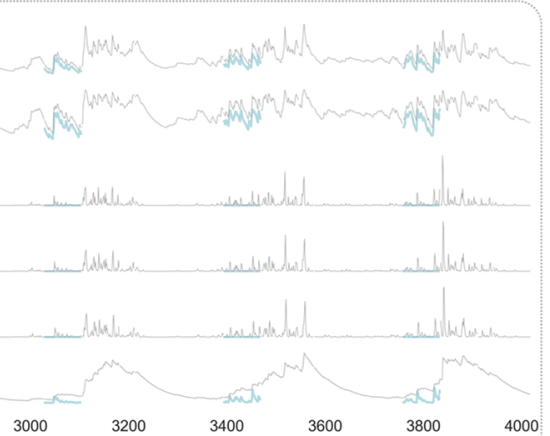

ํㅗㄴ 200

ज्ञ ${ }^{100}$

₹r $\begin{array}{r}25 \\ \times\end{array}$

\begin{tabular}{ll|} 
यै $^{2}$ & 25 \\
& 0
\end{tabular}

$\stackrel{m}{\times}^{25}$

$\stackrel{n}{\times}^{100} \mid$
Legend:

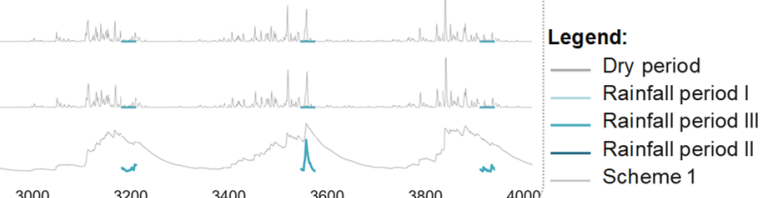

Figure S8. State variables assessment. All state variables (including $X H_{U Z} X C_{U Z} X_{q 1}, X_{q 2}, X_{q 3}$, and $X_{s}$ ) for five schemes in the whole verification period in Hanzhong basin. 
5 Convergence assessment in Mumahe basin and Xunhe basin

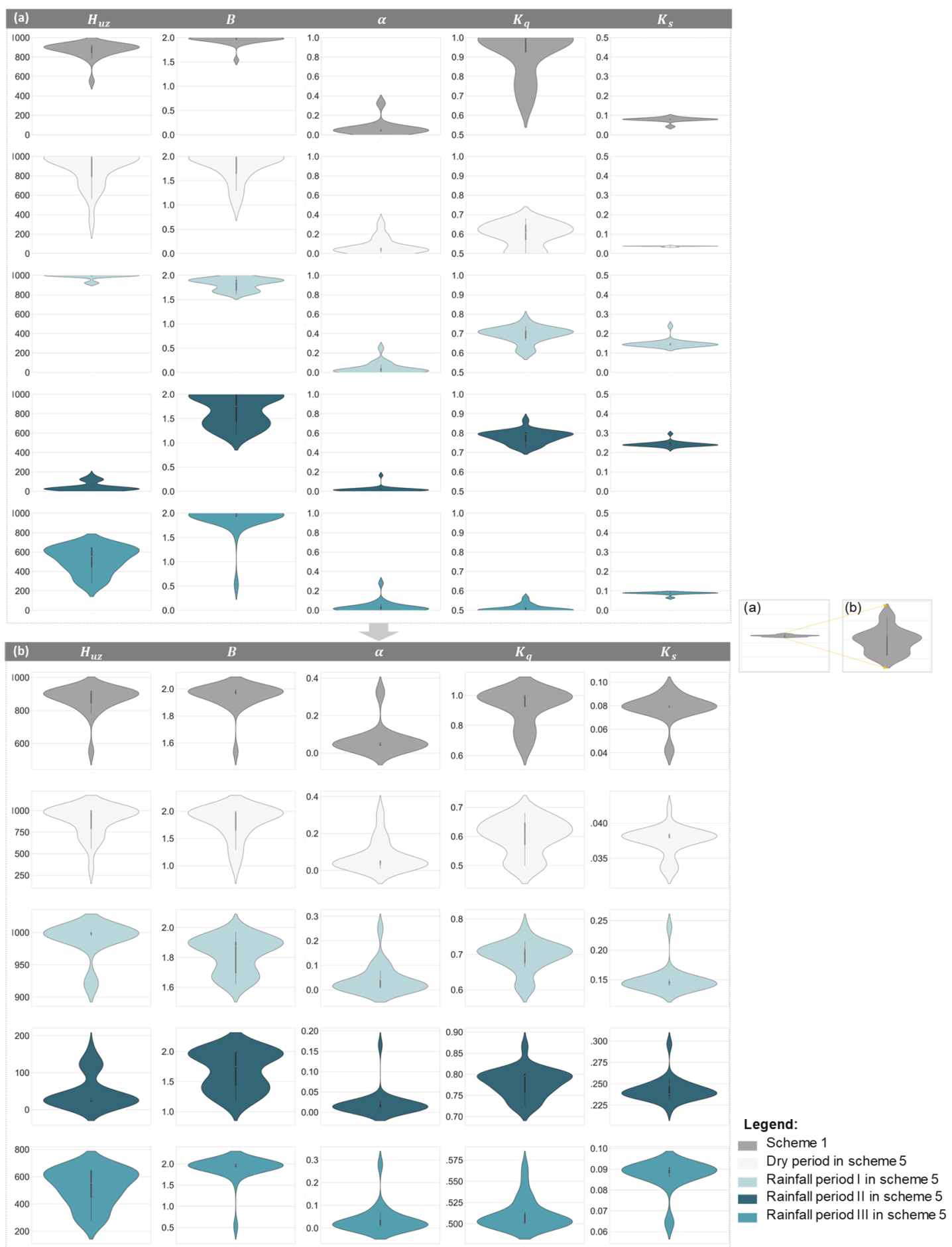

Figure S9. Convergence assessment. Convergence performance for scheme 1 and scheme 5 in Mumahe basin. 


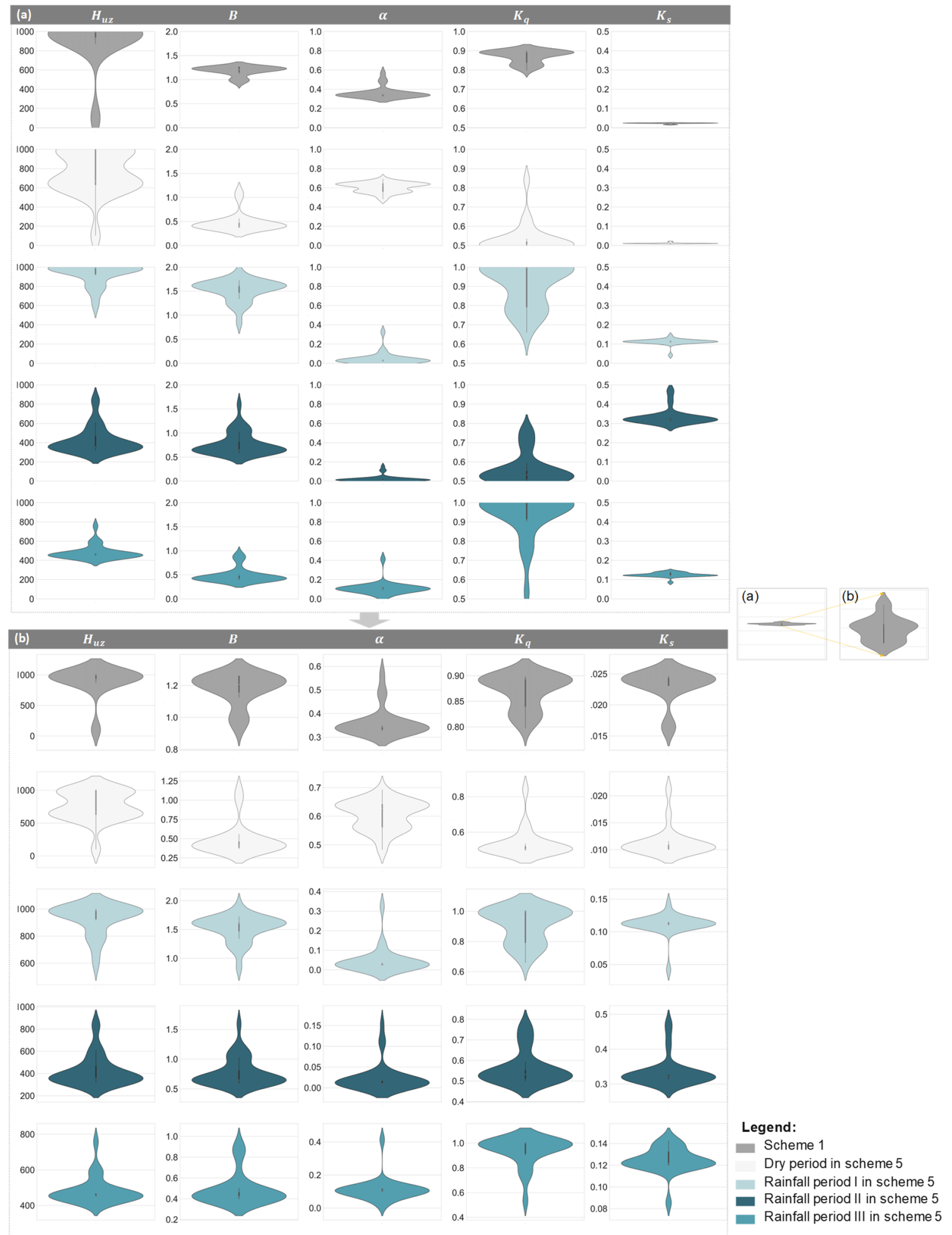

Figure S10. Convergence assessment. Convergence performance for scheme 1 and scheme 5 in Xunhe basin. 


\section{References}

Chen, K. L., Mei, J. J., Rehren, T., and Zhao, C. C.: Indigenous production and interregional exchange: late second-millennium BC bronzes from the Hanzhong basin, China, Antiquity, 90, 665-678, https://doi.org/10.15184/aqy.2016.94, 2016.

Cheng, L., Yaeger, M., Viglione, A., Coopersmith, E., Ye, S., and Sivapalan, M.: Exploring the physical controls of regional

5 patterns of flow duration curves \&ndash; Part 1: Insights from statistical analyses, Hydrol Earth Syst Sc, 16, 4435-4446, 10.5194/hess-16-4435-2012, 2012.

Coopersmith, E., Yaeger, M. A., Ye, S., Cheng, L., and Sivapalan, M.: Exploring the physical controls of regional patterns of flow duration curves \&ndash; Part 3: A catchment classification system based on regime curve indicators, Hydrol Earth Syst Sc, 16, 4467-4482, 10.5194/hess-16-4467-2012, 2012.

10 De Vos, N. J., Rientjes, T. H. M., and Gupta, H. V.: Diagnostic evaluation of conceptual rainfall-runoff models using temporal clustering, Hydrological Processes, 24, 2840-2850, https://doi.org/10.1002/hyp.7698, 2010.

Duan, Q. Y., Gupta, V. K., and Sorooshian, S.: Shuffled complex evolution approach for effective and efficient global minimization, Journal of Optimization Theory and Applications, 76, 501-521, 10.1007/bf00939380, 1993.

Duan, Q. Y., Sorooshian, S., and Gupta, V. K.: Optimal use of the SCE-UA global optimization method for calibrating 15 watershed models, J. Hydrol., 158, 265-284, https://doi.org/10.1016/0022-1694(94)90057-4 1994.

Duan, Q., Sorooshian, S., and Gupta, V.: Effective and efficient global optimization for conceptual rainfall - runoff models, Water Resources Research, 28, 1015-1031, 10.1029/91WR02985, 1992.

Eckhardt, K., and Arnold, J. G.: Automatic calibration of a distributed catchment model, Journal of Hydrology, 251, 103-109, https://doi.org/10.1016/s0022-1694(01)00429-2, 2001.

20 Fang, J., Song, Y., Liu, H., and Piao, S.: Vegetation-climate relationship and its application in the division of vegetation zone in China, Acta Botanica Sinica, 44, 1105-1122, 2002.

Hintze, J. L., and Nelson, R. D.: Violin plots: a box plot-density trace synergism, The American Statistician, 52, 181-184, https://doi.org/10.2307/2685478, 1998.

Khakbaz, F., and Kazeminezhad, M.: Work hardening and mechanical properties of severely deformed AA3003 by constrained

25 groove pressing, Journal of Manufacturing Processes, 14, 20-25, https://doi.org/10.1016/j.jmapro.2011.07.001, 2012.

Kim, D., and Kaluarachchi, J.: Predicting streamflows in snowmelt-driven watersheds using the flow duration curve method, Hydrol Earth Syst Sc, 18, 1679-1693, 10.5194/hess-18-1679-2014, 2014.

Li, Z. J., Liu, P., Deng, C., Guo, S. L., He, P., and Wang, C. J.: Evaluation of Estimation of Distribution Algorithm to Calibrate Computationally Intensive Hydrologic Model, J Hydrol Eng, 21, 04016012, https://doi.org/10.1061/(asce)he.1943$30 \quad 5584.0001350,2016$.

Lin, K. R., Zhang, Q., and Chen, X. H.: An evaluation of impacts of DEM resolution and parameter correlation on TOPMODEL modeling uncertainty, J. Hydrol., 394, 370-383, https://doi.org/10.1016/j.jhydrol.2010.09.012, 2010. 
Moore, R. J.: The probability-distributed principle and runoff production at point and basin scales, Hydrological Sciences Journal, 30, 273-297, 10.1080/02626668509490989, 1985.

Pathiraja, S., Anghileri, D., Burlando, P., Sharma, A., Marshall, L., and Moradkhani, H.: Time-varying parameter models for catchments with land use change: the importance of model structure, Hydrol Earth Syst Sc, 22, 2903-2919, 10.5194/hess-225 2903-2018, 2018.

Pfannerstill, M., Guse, B., and Fohrer, N.: Smart low flow signature metrics for an improved overall performance evaluation of hydrological models, Journal of Hydrology, 510, 447-458, https://doi.org/10.1016/j.jhydrol.2013.12.044, 2014.

Pugliese, A., Castellarin, A., and Brath, A.: Geostatistical prediction of flow-duration curves in an index-flow framework, Hydrol Earth Syst Sc, 18, 3801-3816, 10.5194/hess-18-3801-2014, 2014.

10 Sorooshian, S., Duan, Q., and Gupta, V. K.: Calibration of rainfall - runoff models: Application of global optimization to the Sacramento Soil Moisture Accounting Model, Water Resour. Res., 29, 1185-1194, https://doi.org/10.1029/92wr02617, 1993. Sun, X., Lu, H., Wang, S., and Yi, S.: Ages of Liangshan Paleolithic sites in Hanzhong Basin, central China, Quat Geochronol, 10, 380-386, https://doi.org/10.1016/j.quageo.2012.04.014, 2012.

Vrugt, J. A., Bouten, W., Gupta, H. V., and Sorooshian, S.: Toward improved identifiability of hydrologic model parameters:

15 The information content of experimental data, Water Resources Research, 38, 48-41-48-13, doi:10.1029/2001WR001118, 2002.

Wagener, T., Boyle, D. P., Lees, M. J., Wheater, H. S., Gupta, H. V., and Sorooshian, S.: A framework for development and application of hydrological models, Hydrol. Earth Syst. Sci., 5, 13-26, 10.5194/hess-5-13-2001, 2001.

Yadav, M., Wagener, T., and Gupta, H.: Regionalization of constraints on expected watershed response behavior for improved 20 predictions in ungauged basins, Advances in Water Resources, 30, 1756-1774, https://doi.org/10.1016/j.advwatres.2007.01.005, 2007. 